\title{
Relações interpessoais em uma instituição de ensino com internato: conflitos e mediações
}

\section{Interpersonal relations in a teaching institution with boarding: conflict and mediation}

\author{
Luciane Baseggio Vendruscolo*, Ana Maria Pasinato Sandi**, Ortenila Sopelsa ***. \\ *Técnica em Educação do Instituto Federal Catarinense- Campus Concórdia, SC; **Supervisora Pedagógica do Instituto Federal \\ Catarinense- Campus Concórdia, SC; *** Professora e Pesquisadora do Programa de Mestrado em Educação das UNOESC.
}

\begin{abstract}
Resumo
$\mathrm{O}$ artigo apresenta dados que questionam o atual instrumento regulador utilizado pela instituição escolar, como mecanismo de mediação e controle dos possíveis conflitos provenientes das relações interpessoais que se estabelecem entre os alunos. Os dados evidenciam que no mundo do internato o instrumento regulador se mostra ineficiente, pois as regras informais prevalecem nas relações interpessoais e, na maioria das vezes são, sim, geradoras de conflitos diante dos arranjos e da organização estruturada pelos alunos. Constatou-se que a Instituição pesquisada precisa melhorar as ações e relações praticadas e cultivadas no cotidiano escolar. Palavras Chave: escola internato, conflitos, mediação
\end{abstract}

\begin{abstract}
The article presents data that question the current regulatory tool used by the educational institution such as mediation and control mechanism for possible conflicts arising from interpersonal relationships established among students. The collected data show that in the boarding ambience the regulatory instrument is shown as inefficient because the informal rules prevail in interpersonal relationships and, for the most part are generating conflicts on the arrangements and organization structured by the students. It was found that the searched Institution needs to improve the actions and relationships practiced and cultivated in everyday school life.

Keywords: Boarding school, conflict, mediation.
\end{abstract}

A instituição escolar exerce grande influência sobre os sujeitos no processo educativo, especialmente quando esses sujeitos são os alunos do ensino médio que, na grande maioria das vezes, buscam encontrar respostas às suas inquietudes em relação aos processos da vida na figura do professor e no trabalho da escola. Mais complexo ainda é quando esses alunos moram na escola, e esta, com toda sua organização, passa a guiar toda a sua conduta.

Sabendo das peculiaridades que emergem no convívio coletivo e diário no internato, diante do número de adolescentes que vivem juntos, das regras de convivência, dos possíveis conflitos decorrentes das relações interpessoais entre os diferentes grupos existentes, o artigo apresenta dados que questionam o atual instrumento regulador utilizado pela instituição escolar como mecanismo de mediação e controle dos possíveis conflitos provenientes das relações interpessoais que se estabelecem entre os alunos.

O presente estudo foi desenvolvido mediante uma pesquisa descritiva, de cunho exploratório e de natureza qualitativa realizado no Programa de Pós-graduação em
Educação (PPGEd) - Mestrado da Universidade do Oeste de Santa Catarina (UNOESC), Campus de Joaçaba (SC), no período de 2012 e 2013 , e teve como principal objetivo investigar a concepção de alunos matriculados sobre o espaço escolar do internato e a dinâmica das relações que ocorrem nesse contexto. A base empírica foi constituída por dados de uma investigação que teve como amostra 174 alunos internos de uma Instituição de Ensino. A coleta dos dados se deu por meio de questionário e de entrevista semiestruturada envolvendo $5 \%$ dos participantes e dois ex-alunos. Para preservar a identidade dos sujeitos participantes da entrevista, os informantes foram identificados com a sigla "Ent", sendo enumerados de forma sequencial, de Ent1 a Ent9, e assim representados nos recortes de suas falas.

\section{Escola Internato: adolescentes e suas relações}

Para compreender o mundo do internato, foco desta pesquisa, o qual se apresenta como residência e instituição formal destinada à educação técnica profissional, onde adolescentes permanecem em tempo integral, sob uma filosofia específica, normas regimentadas e disciplinadoras, o entendimento do termo "instituição total" definido por Goffman (2010) é fundamental para desvelar as relações que ocorrem entre os alunos internos. Segundo esse autor, a instituição total é "[...] um local de residência e trabalho onde um grande número de indivíduos com situação semelhante, separados da sociedade mais ampla por considerável período de tempo, levam uma vida fechada e formalmente administrada." (Goffman, 2010, p. 11). Esse mesmo autor enumera a grosso modo, as instituições totais em cinco agrupamentos, entre elas, a que interessa para esta pesquisa, as escolas internas.

De acordó com Goffman (2010) "nas instituições totais, existe uma divisão básica entre um grande grupo controlado, que podemos denominar o grupo dos internados, e uma pequena equipe de supervisão" (Goffman, 2010, p. 18).

Consoante com o processo de adaptação ao novo ambiente, aos novos colegas e às normas da Instituição, definidos por Goffman (2010) como ajustamentos primários, o novato depara-se também com o que o autor definiu de "ajustamentos secundários", ajustamentos esses que emergem nesse ambiente e se constituem "sistema de privilégios", criados e 
organizados por seus internos e que não são permitidos pela Instituição. “Os ajustamentos secundários dão ao internado uma prova evidente de que é ainda um homem autônomo, com certo controle de seu ambiente; às vezes, um ajustamento secundário se torna quase uma forma de abrigo para o eu [...]."'(Goffman, 2010, p. 54). É nesses ajustamentos que estruturam-se as relações entre os internos, sob os arranjos e acordos criados naquele ambiente.

Esses códigos e regras informais, criados pelos internos, orientam muitas das condutas no mundo dos internados. "A partir da presença de ajustamentos secundários, podemos predizer que o grupo de internados criou algum tipo de código e alguns meios de controle social informal para impedir que um internado informe a equipe dirigente quanto aos ajustamentos secundários de outro." (Goffman, 2010, p. 54-55). É possível observar nesses ambientes uma sociedade em miniatura e estruturada, utilizando-se do poder de controle, organizada pelos diferentes grupos existentes no mundo do internato, e cada grupo ocupa o seu devido lugar, conforme os ajustamentos que foram criados.

Por meio dos estudos de Goffman (2010), podemos perceber detalhadamente a rotina institucional de um internato, pois, com muita sutileza, ele vai desvelando a aparente camuflagem presente no não "dito institucional", porém ativo e atuante, pois opera de forma contínua no cotidiano, tornando-se visível, portanto dizível, sob uma ordenação e vigilância, que exigem o disciplinamento do interno. O Regimento, criado pela Instituição, sem a participação dos alunos, é o instrumento normatizador do internato, dispositivo utilizado para manter a ordem no ambiente, atendendo aos padrões institucionais.

Foucault (1987), em sua obra "Vigiar e punir", indaga a respeito dos "mecanismos" que ao longo dos tempos têm sido adotados e que têm como alvo o sujeito. Ao tratar da "disciplina", enfoca no "poder disciplinar e normalizador" e permite vislumbrar como a normatização opera nas instituições escolares, configurando-se ao longo da história em relações de poder que incidem na hierarquização e estratificação dos indivíduos.

Foucault (1987, p. 122) explica que no "Colégio: o modelo de convento se impõe pouco a pouco; o internato aparece como o regime de educação senão o mais frequente, pelo menos o mais perfeito." Assim, o modelo de escola internato veio estruturando-se ao longo da história, sob uma lógica de que é necessário enclausurar o aluno para melhor trabalhá-lo, lapidá-lo, por meio de "normas" que regulamentam e desenvolvem uma educação padronizada que visa a uma conduta moral de comportamentos "adequados", "controlados". A formação de grupos distintos, bem como suas relações, são perceptíveis nesses ambientes, originando em alguns momentos conflitos, em outros, confraternizações, ou até mesmo uma organização repentina, movida, é claro, por interesse mútuo. Desse modo, é possível também que nos deparemos, nesses ambientes, com situações que geram algum tipo de violência.
Sendo os internos, adolescentes, é relevante destacar a importância que devemos dar à parte afetiva nessa fase, por ser um período, de modo geral, de maior instabilidade emocional. No internato, os adolescentes deparam-se com muitas situações características dessa fase, que envolvem o campo físico, emotivo, ético, social e cultural, e os encaminhamentos ora adotados na Instituição serão determinantes nas conduções futuras relacionadas a todos esses aspectos, quando esses jovens estiverem na vida adulta. Conforme salienta Campos (2011, p. 36) "os adolescentes [...] devem ser considerados biossocialmente, com a devida ênfase nos sistemas de valores e pressões dos grupos que os circulam e com ênfase, às vezes, nos valores em conflito, dos múltiplos papéis que precisa assumir".

Compreender o aluno adolescente interno significa adentrar em seu mundo. Como escola, avaliar o contexto no qual esse aluno está inserido, os objetivos que o trouxeram para a nossa Instituição, sua convivência no internato, os diferentes grupos e interesses representados no cotidiano, as causas dos conflitos presentes no ambiente internato e as possíveis implicações para o desenvolvimento biopsicossocial, já que, a partir de suas vivências, elaboram-se definições de comportamentos que influenciam e determinam a construção de seu eu.

Wallon (1975, p. 390), enfatiza que "é necessário não dissociar o indivíduo das situações em que ele se encontra. Que uma conduta é sempre um resultado do conjunto formado pela situação e pelo sujeito nela implicado." Sendo assim, todas as situações vividas no internato pelos adolescentes estão diretamente imbricadas ao ser e ao fazer escola. A escola internato torna-se o meio físico e social principal para esses adolescentes, constituindo-se a estrutura base de solidificação de saberes que serão transferidos para o viver desses internos.

Os integrantes desse ambiente buscam amparo entre si, aceitação, lealdade, socializam sonhos e enfrentam dificuldades comuns à sua idade. As definições estabelecidas nesse ambiente e socializadas tornam-se parâmetros para compor o eu de cada integrante do internato. Wallon (1975, p. 202-203) destaca ainda em seus estudos a importância da sociabilidade nesse processo de desenvolvimento:

O meio [...] é complementar duma maneira estreita, duma maneira necessária, duma maneira inevitável ao ser vivo. O ser vivo adapta-se a um certo meio segundo as suas próprias necessidades e segundo os meios à sua disposição de as satisfazer.[...] O meio começa por ser, para todos os seres vivos, um meio físico. Mas o que caracteriza a espécie humana é o fato de ela ter substituído ou sobreposto ao meio físico um meio social.

De acordo com Vygotsky (2003) a interação e o diálogo no cotidiano escolar são formas de objetivação dos conhecimentos humanos, de constituir-se e constituir, num processo contínuo, tendo como referencial determinações sociais construídas histórica e 
culturalmente no ambiente. Assim, o viver junto exige cuidado, atenção, acompanhamento, pois esse meio representa também a família desses adolescentes, tornando-se modelo ideológico consolidador de valores, repercutindo determinadas condutas a partir das interações sociais existentes.

A escola, por intermédio de seus processos de ensino e de aprendizagem, pode transformar a estrutura existente, permitindo construir novas aprendizagens, significar novos conceitos e valores que possibilitem ao educando enxergar além do seu meio. De acordo com Vygotsky (2003, p. 77-78), devemos considerar dois aspectos fundamentais na educação:

Em primeiro lugar, o fato de que a meta da educação não é a adaptação ao ambiente já existente, que pode ser efetuada pela própria vida, mas a criação de um ser humano que olhe para além de seu meio. [...] Em segundo lugar, devemos levar em conta que os elementos do meio também podem influenciar de forma nociva e funesta um organismo jovem. Não nos esqueçamos que não se trata de um sujeito já formado, mas de um organismo em crescimento, mutante e frágil, e que muito do que é aceitável para um adulto é funesto para uma criança.

A qualidade ou não das apropriações que são mediadas nesse processo incidem sobre o desenvolvimento do sujeito, sendo um constituir constante. Saber como esses jovens em crescimento e maturação lidam com os conflitos diários, as pressões, as diferenças existentes e como isso se integra à sua subjetividade, é uma necessidade da escola, pois conduz esse processo no desenvolvimento diário em suas atividades. Por meio da interação, da troca, das negociações, utilizando-se de ferramentas como a linguagem, o ser humano realiza a sua compreensão de mundo. Dessa maneira, mais do que o indivíduo agir, o (inter)agir nesse processo, permitindo a participação de cada ser no coletivo, e escola enquanto instituição educativa podem mediar esse processo de construção do ser humano no cotidiano escolar, criando possibilidades de diálogo que permitam ao adolescente integrar-se ao mundo social, resolver conflitos de forma participativa, crítica e ética, resistindo a modos de vida que vêm sendo implantados, ultrapassando modelos estabelecidos culturalmente e que podem ser melhorados e reelaborados.

\section{A dinâmica das relações e os conflitos resultantes dessa organização na escola internato}

Ao receber os alunos no internato, a instituição entrega a todos eles cópia do Regulamento Disciplinar e cópia do Regulamento de Moradia visando garantir que todos conheçam e cumpram o que está regimentado, fiscaliza e acompanha os alunos mediando os possíveis conflitos e a forma de se relacionar seguindo as orientações estabelecidas nos Regulamentos. Porém, conforme o referencial teórico apresentado, é possível observar nesses ambientes uma sociedade em miniatura e estruturada, utilizando-se do poder de controle, organizada pelos diferentes grupos existentes no mundo do internato, onde cada grupo ocupa o seu devido lugar, conforme os ajustamentos que foram criados, a fim de garantir alguns "privilégios" que lhes permitem atuar com restrita autonomia. É nesse espaço que surgem as regras informais.

Buscando conhecer a existência dessas regras informais no internato questionou-se os sujeitos participantes da pesquisa sobre as normas informais estabelecidas pelos alunos internos no regime de moradia e obteve-se o seguinte resultado: $75,29 \%$ dos alunos pesquisados responderam "sim" a essa questão e $24,71 \%$ responderam que "não" existem regras informais. Nessa direção, Goffman (2010, p. 49) destaca que "[...] ao mesmo tempo em que o processo de mortificação se desenvolve, o internado começa a receber instrução formal e informal a respeito do que aqui será denominado sistema de privilégios". A afirmação de que as regras informais prevalecem na convivência no internato também é contemplada nos relatos dos sujeitos pesquisados que participaram da entrevista.

Lá no alojamento mais são as regras informais, tudo oque os alunos impõem. (Ent5)

É uma regra informal, vamos dizer, funciona do lado bom e do lado ruim, cada um ali tem um pensamento. (Ent6)

Olha, na verdade, tem a regra do regimento, mas no bloco não adianta muito. Então, acabam prevalecendo as nossas regras. (Ent7)

Sendo as regras informais, segundo os sujeitos da pesquisa, determinantes no convívio no ambiente internato, é importante conhecer o que elas representam para os internos. Constatou-se que $82,18 \%$ dos participantes indicaram a alternativa, "elas têm muita importância, pois é uma forma encontrada pelos internos para viver no internato".

Na busca pela compreensão da natureza dessas regras, perguntou-se aos alunos: Quem estabelece a grande maioria das regras informais? "A terceira série" foi indicada como responsável pela determinação das regras por $65,54 \%$ dos alunos. Evidencia-se nas respostas dos sujeitos entrevistados algumas regras que são determinadas pela referida série.

O terceiro ano que é maior, mais velho, estipula as regras informais, aí ele chega lá e fala, e o aluno tende a obedecer. [...] Primeiro ano tem que dar dinheiro para terceiro ano ou pagar coca, ou qualquer coisa assim, às vezes dar objetos pessoais também. (Ent8)

Entraram em três no nosso quarto, na segunda noite e falaram é assim que funciona: Vocês têm que baixar a cabeça." Devem buscar as coisas que precisamos[...] Tem uma roupa bonitinha, me empresta que eu quero usar". "Lava minha roupa." Eles não querem mandar para a lavanderia, eles 
mandam você lavar as roupas deles. "Cuida a máquina que está batendo, e se não estiverem todas as minhas roupas aí, você vai pagar.” (Ent3)

Verifica-se nas narrativas dos sujeitos entrevistados que as regras informais instituídas pelos alunos colocam à prova a eficiência do Regulamento Disciplinar que vigora na Instituição, mediante a manipulação exercida pelos grupos que lideram a organização informal no internato. Os exemplos apresentados pelos sujeitos pesquisados elucidam algumas situações que ocorrem no internato sob a orientação das regras informais:

Uma das coisas é quando o terceiro vinha lá no quarto, pegava um aluno do primeiro e ia lá pra limpar o quarto, "você tem que limpar o quarto pra nós”. Eu considero isso errado, a pessoa devia se conscientizar e saber que cada um tem o dever de limpar o seu quarto, não de limpar o quarto do outro, porque, se foi ele quem sujou, ele que deveria limpar, não ir lá pegar um aluno do primeiro pra extorquir. (Ent8)

Aos olhos de quem fiscaliza a rotina no internato, o cumprimento do que está estabelecido para os alunos no regimento institucional parece estar normal e tudo sob controle, mas os relatos dos alunos revelam os arranjos que ocorrem sob a determinação das regras informais, inclusive algumas delas se mostram com características repressivas e oportunistas. Revela o processo coercitivo resultante dessas ações na forma estruturada das relações humanas presentes naquele espaço, por meio das minúcias de controle implantadas e praticadas.

Outro argumento apresentado pelos sujeitos pesquisados refere-se aos acordos entre os alunos em relação à aplicação das penas previstas no regimento, pois, quando não há a prova concreta sobre quem de fato cometeu a infração, eles organizam-se para que as consequências sejam as menores possíveis, com o propósito de garantir a permanência dos alunos no internato. De acordo com o relato de um dos alunos, nem sempre o aluno que sofre as sanções punitivas da instituição é de fato o infrator.

A questão de troca de favores entre aluno também existe. Às vezes, tem vários alunos que vão sofrer um processo junto, e alguém tem a ficha mais suja e pode sofrer a pena mais grave por causa disso, simplesmente os demais do grupo pegam e assumem sozinhos a culpa de determinada situação, qualquer coisa que tenha acontecido, livrando a barra dessa pessoa. Uma troca de favores; e também é comum, simplesmente ao invés de dez serem punidos, um vai lá e diz: "Eu fiz sozinho”. Só aquele é punido, também acontece isso. (Ent2)

A união dos alunos em torno das questões relativas às punições que lhes são cabíveis por causa do envolvimento dos mesmos em situações de inobservância ao que está estabelecido no Regulamento chama a atenção. Sobre o sistema disciplinar vigente na Instituição, apresenta-se um argumento de um sujeito entrevistado que demonstra a vontade de participação dos alunos na construção de novas normas regimentais:

O sistema está montado, no momento que alguém desafia ou questiona o sistema, é muito mais prático estar transferindo o aluno ou punindo o aluno, independente da forma que eles utilizam-se para isso, do que eles procurar corrigir o sistema nas falhas que tem. Até em meio a essas questões, às vezes, alunos são punidos indevidamente sim. (Ent2)

Compreende-se que é tempo de movimentos que desafiam os sujeitos em relação a mudanças nas atuais estruturas organizacionais de nossas instituições escolares e que estas permitam a participação coletiva de todos e a valorização de novos saberes. Nesse sentido, Alarcão (2001, p. 18) questiona:

Que tempo e espaço de iniciativas concedemos aos nossos alunos? E aos nossos professores? E aos alunos, professores e funcionários em conjunto? É tempo de convivência saudável e de cooperação. Como aproveitamos essas qualidades tão características da juventude e tão saudáveis para os profissionais que trabalham em conjunto? É tempo de turbulência. Como a controlamos, sem excessos e sem repressões não compreendidas?

Os resultados da investigação efetuada indicam a ausência de espaços para o diálogo, a reflexão e a avaliação crítica de nossa prática escolar envolvendo todos os atores que vivem nesse ambiente, no que se refere principalmente ao internato, à sua organização e às relações interpessoais presentes. Outra narrativa de um sujeito entrevistado demonstra nitidamente a separação entre as diferentes séries e a atuação dos alunos já internos sobre os novatos:

Normalmente, cada ano é um núcleo fechado. [...] Aqui, não basta você ter que conviver com mais de cem pessoas, você tem uma divisão entre anos, que é primeiro ano, segundo e terceiro ano, e cada público você tem que se comportar de uma maneira diferente [...] cada grupo existe um tratamento especial, nas regras, digamos assim, do internato. (Ent2)

No relato do sujeito Ent2, há a indicação de que as relações interpessoais diferem entre as séries, e são estabelecidas pelos alunos por meio das regras informais, e, para cada série, são bem específicas. Diante disso, cabe refletir: que norma de convivência é essa produzida no interior dessa instituição escolar que faz com que os adolescentes precisem comportar-se diferentemente perante as pessoas e de acordo com o nível em que se encontram, ora submissos, ora iguais, ora superiores, exigindo obediência e submissão?

É preciso assumir, como educadores, que constrói-se a escola - e as relações presentes nela - a partir de nossas ações, por meio da prática educativa diária. Cabe avaliar se o atual projeto educativo institucional nos oferece suporte necessário para quebrar esse ciclo 
repetitivo que tem se tornado uma verdade no conviver entre os internos e assegurado esse modelo de relações pautadas em interesses e muitas vezes geradoras de conflitos.

Sobre a existência de conflitos interpessoais no Internato, a partir dos dados coletados obteve-se os seguintes resultados: $92,53 \%$ dos sujeitos responderam "sim" e 7,47\% dos sujeitos responderam que não existem conflitos. Ao serem questionados sobre os tipos e causas de conflitos que ocorrem no internato obtivemos o seguinte resultado: $1^{\circ}$ Discussões e empurrões; $2^{\circ}$ Humilhações com palavrões; $3^{\circ}$ Ameaças/chantagem; $4^{\circ}$ Agressão psicológica ou física; $5^{\circ}$ extorsão.

É possível confirmar também no relato dos alunos o registro de conflitos.

Eles se xingam bastante [Silêncio, o aluno enche os olhos de lágrimas]. Fico um pouquinho inseguro, às vezes dá um pouco de medo Sempre tem alguma coisa acontecendo lá. (Ent5)

Nem todos se comportam bem com o outro, assim. [...] Conflito verbal é mais comum. Físico não é tão comum, mas acontecem. (Ent7).

Avalia-se a necessidade de compreensão das manifestações de conflitos confirmados na pesquisa, bem como considerar as formas de validação e as relações interpessoais que se estabelecem e se fazem presentes e ativas no âmbito escolar, pois ambas assumem papel preponderante nas manifestações ou não dos conflitos que resultam em violência. Os registros sobre as situações vividas resultantes de conflitos no internato podem revelar sentimentos de mágoa e raiva.

Assim, tem uns que dá vontade de pegar [...] Olha! Eu passei as minhas ali dentro. Isso dá raiva, se você vê a pessoa assim, da raiva porque eu não fazia mal a ninguém, às vezes emprestava os trabalhos, ajudava, e o pessoal ficava tirando sarro, ficava incomodando. (Ent9)

Com o intuito de promover reflexões mais profundas sobre os dados que se apresentaram na pesquisa, recorro às sábias palavras de Aquino (2003, p. 22): “[...] mais do que constatar ou denunciar aonde chegamos, o importante é indagar porque permanecemos aonde chegamos. O que importa aqui é compreender a lógica dos fazeres ordinários que ordenam os cotidianos das escolas [...]". Cabe uma auto avaliação de todas as ações desenvolvidas no âmbito da Instituição pesquisada, a fim de reconhecer a necessidade de uma reestruturação na forma de pensar e gerir o internato nessa escola, com o intuito de reestruturá-lo e organizá-lo apoiado no pensamento democrático. Sobre essa possibilidade de construir na escola um ambiente democrático, Aquino (2003, p. 62) explica: "Eis aqui portanto, o segredo da vitalidade democrática: escolas explicitamente comprometidas com o modo de vida democrático, cujos dispositivos de organização cotidiana garantam uma ambiência justa e respeitosa, além de competente. Em suma: só se ensina democracia fazendo democracia".

O momento histórico atual requer dos educadores outro pensamento em relação às questões que envolvem o viver na escola, e nessa reflexão há a necessidade de que seja repensado o atual regimento disciplinar em razão de todas as questões apontadas pelos alunos e analisadas nesta pesquisa. Sobre esses dispositivos da disciplina adotados pelas escolas, Aquino (2003, p. 20) ressalta: "mais drasticamente: forjaram-se medidas de enquadramento penal dos hábitos do alunado, de acordo com regulamentos, estatutos, códigos múltiplos." Essa observação do autor é verdadeira e está muito presente nas instituições escolares. Compreende-se que os educadores estão diante de uma situação bastante conflitante, pois a estrutura no que diz respeito às questões organizacionais das escolas, na atualidade, guardadas as devidas proporções, ainda se encontram arraigada nas descobertas do século XVIII, pois, a partir desse período, o tempo e o espaço escolar organizaramse mediante o exercício do poder disciplinar por meio de sanções normalizadoras.

\section{Considerações finais.}

Os dados da pesquisa evidenciam que no mundo do internato o instrumento regulador se mostra ineficiente para mediar e controlar os possíveis conflitos provenientes das relações interpessoais que se estabelecem entre os alunos diante dos arranjos e da organização estruturada pelos alunos, pois as regras informais prevalecem nas relações interpessoais. E, de forma explicita, revelaram-se regras repressivas, hierárquicas e escalonadas nas relações de convivência entre as diferentes séries, sendo, na maioria das vezes geradoras de conflitos.

Entre as situações mais graves desses arranjos revelados na pesquisa destacam-se as determinações aos considerados submissos, em sua grande maioria os novatos, a execução de atividades que são fiscalizadas no lugar de quem ordena, situações em que nem sempre o aluno punido pela escola é de fato o infrator, a regra do silêncio, da cobrança de valores, mercadorias, lanches, da proteção e amizade.

Faz-se oportuno (re)pensar um projeto de escola contextualizado, participativo, capaz de envolver os profissionais que atuam na instituição, e todos os alunos, para que se sintam efetivamente sujeitos do processo, possibilitando a construção de novos saberes e novas formas de mediação na resolução dos problemas. Entrever, assim, que tal ação, não se configura como algo que está pronto, verdadeiro e impessoal, e sim, como algo que precisa ser (re)inventado, (re)construído e (re)significado em um processo permanente, com o propósito de gerar pensamentos e práticas nas relações interpessoais pautadas no respeito e na autonomia, perspectivando a formação humana e ética tão necessária e discutida na contemporaneidade.

\section{Referências}

ALARCÃO, Isabel. Escola reflexiva e nova racionalidade. Porto Alegre: Artmed, 2001. 
AQUINO, Julio Groppa. Indisciplina: o contraponto das escolas democráticas. São Paulo: Moderna, 2003. (Coleção cotidiano escolar).

CAMPOS, Dinah Martins de Souza. Psicologia da adolescência: normalidade e psicopatologia. 23. ed. Petrópolis, Vozes, 2011.

FOUCAULT, Michel. Vigiar e punir: nascimento da prisão. Tradução Raquel Ramalhete. 25. ed. Petrópolis: Vozes, 1987.
GOFFMAN, Erving. Manicômios, prisões e conventos. Tradução Dante Moreira Leite. 8. ed. São Paulo: Perspectiva, 2010.

VYGOTSKY, Lev Semenovitch. Psicologia pedagógica. Tradução Cláudia Schilling. Porto Alegre: Artmed, 2003.

WALLON, Henri. Psicologia e educação da infância. 1975.

Tradução de Ana Rabaça. Lisboa: Editorial Estampa, 